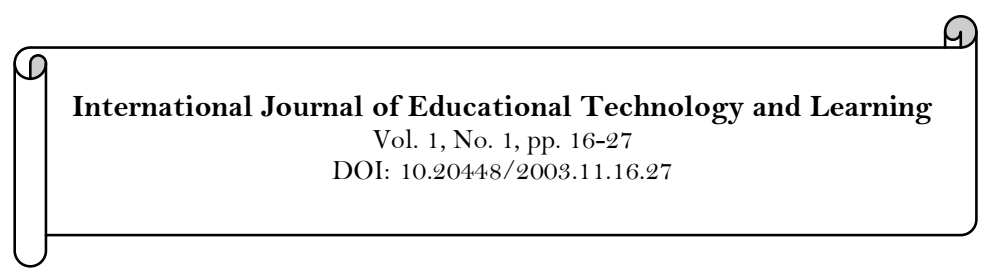

\title{
Teaching Reading Skills to Learners with Down Syndrome
}

\author{
Sandro Sehic ${ }^{1}$ \\ ${ }^{1}$ MVCC Education Opportunity Center, 524 Elizabeth St., Utica, NY, USA.
}

Abstract
\begin{tabular}{l|l} 
Learning to read is a challenging cognitive process that requires the & Keywords: \\
memorization of new symbols, phonemic awareness, and the & Down syndrome \\
Reading & \\
construction of meaning. This cognitive process may be especially & Reading skills \\
challenging for learners with Down syndrome. A genetic disorder & Teaching skills. \\
that causes mild to moderate intellectual disabilities, Down & Licensed: \\
syndrome may no longer be viewed as completely eliminating & This work is licensed under a \\
learners' ability to learn to read. With early intervention and proper & Creative Commons Attribution \\
teaching and learning methods, learners with Down syndrome can & 4.o License. \\
learn to read and improve their existing reading skills. Therefore, the & Publisher: \\
purpose of this research article is to provide information about & Scientific Publishing Institute \\
certain teaching strategies that may enable teachers to help learners \\
with Down syndrome learn to read and improve their existing
\end{tabular}
reading skills.

\section{Introduction}

Learning is defined as the acquisition of new knowledge and skills. The learning process is not easy especially when learners have been diagnosed with learning and intellectual disabilities. Students with special needs learn differently from their peers of the same age. Their learning success (unfortunately) depends to a great extent on the degree of their learning or intellectual disability. Learning disabilities and intellectual disabilities are mental-cognitive barriers that disrupt learning process by preventing learners from acquiring new information and skills in a desirable manner. A special brain has special needs and requires special instructions to receive, process, and store certain information.

Over the centuries, many different educators, psychologists, and philosophers have attempted to solve the mystery of the human comprehension process. Educators (teachers) agree that humans acquire knowledge in many different ways depending on their learning styles, aptitudes for learning, and previous knowledge. However, understanding the learning styles and needs of regular students is relatively easier than understanding those of students with special needs. How a special brain acquires and processes new information is still a great mystery, and educators and psychologists are constantly researching the subject. If they understand how the special brain works, educators (teachers) can adopt (or prescribe) proper teaching methods or therapies that will facilitate the learning process of students with special needs.

The purpose of this research paper is to explore teaching and learning styles that facilitate the reading/learning process of learners who have been diagnosed with Down syndrome. Various intellectual and physical disabilities that may severely disrupt the learning process impact learners with Down syndrome unlike many learners with learning disabilities. Down syndrome and other conditions that cause intellectual and physical disabilities require a special approach by educators. Such an approach enables them to determine the learners' cognitive and physical abilities in order to instruct them using proper teaching methods and possibly place them in a special learning environment that will help them achieve the desired learning objectives.

The purpose of this research paper is not to create new teaching methods or to find therapies that will assist learners with Down syndrome. Rather, it is to explore learning and teaching methods that are appropriate for learners with Down syndrome and can benefit teachers and learners equally.

\section{Physical and Intellectual Features of Down syndrome}

Down syndrome is a chromosomal abnormality that a British physician, John Langdon Down, first detected and studied in 1866. However, it was not recognized as a chromosomal disorder until 1959. "In 1959 a French physician, Jerome Lejeune, discovered that the syndrome was caused by an extra chromosome" (Down, 2008). Down syndrome is defined as "the collection of birth defects caused by an extra chromosome." 
(Hildyard, 2003). That means that the number of chromosomes is greater in Down syndrome patients than in people without the abnormality.

Normal people are born with 46 chromosomes, 23 inherited from each parent.

These chromosomes carry the genes, which are the chemical messages that

determine how we will develop. Some babies are born with an extra chromosome

known as trisomy 21. As a result, they develop abnormally in several ways.

(Hildyard, 2003)

Down syndrome results from the presence of extra chromosome known as trisomy 21 . It is important for all educators to know that it takes three forms: trisomy 21, the mosaic form, and translocation. Trisomy 21 , the most common form of Down syndrome, affects about $94 \%$ of all individuals with the disorder. "Trisomy 21 occurs following faulty chromosomal distribution in the formation of the sperm or egg prior to fertilization. Specifically, non-dysjunction during meiosis results in either the sperm or the egg having an extra $21^{\text {st }}$ chromosome" (Down, 2005).

In the mosaic form of Down syndrome, "non-dysjunction occurs after fertilization during one of the initial cell divisions. When this takes place, the individual has a mixture of cells containing 46 and 47 chromosomes" (Down, 2005). Moreover, translocation the third form of Down syndrome, "occurs when part of the $21^{\text {st }}$ chromosome becomes detached from the rest of the chromosome during cell division and attaches to another chromosome" (Down, 2005).

According to the National Down Syndrome Society, "one in 691 babies are born with Down syndrome. There are more than 400,000 people living with Down syndrome in the United States" (National Down Syndrome Society, 2011). Down syndrome is more common among males than females. According to the Cambridge Encyclopedia of Childhood Development, "there are slightly more males born with DS than females (1.3:1)" (Down, 2005). Also, according to Hanson (1987) "there are approximately 7,000 children with Down syndrome born in the United States each year" (p. 19).

Down syndrome basically results from the presence of an extra $\left(47^{\text {th }}\right)$ chromosome. Scientists are still debating the cause of its appearance. Studies show that the age of the mother may correlate with the appearance of the extra chromosome and that Down syndrome is not tied to race and socioeconomic status.

Down syndrome occurs in approximately 1 in 600 to 650 live births and is associated with advanced maternal age, particularly over 35 years of age. The incidence is as high as 1 in 80 for offspring of women above 40 years of age. In cases caused by translocation, which is a genetic aberration that is hereditary rather than a chromosomal aberration caused by nondisjunction during cell division, the incidence is not associated with maternal age and the risk is low, about 1 in 5 if the mother is carrier and 1 in 20 if the father is the carrier. (Down, 2009)

It is worth nothing that the majority of children with Down syndrome are born before their mothers reach $35^{\text {th }}$ birthday and a great majority of children whose mothers have Down syndrome inherit this chromosomal abnormality.

Eighty percent of children with down syndrome are born to women under 35

years or age, but the incidence of Down syndrome births does increase with age.

Approximately $5 \%$ of cases are transmitted by the sperm. Amniocentesis or

chorionic villus sampling can be used to detect the disorder in the fetus. Children

born to women with Down syndrome have a $50 \%$ chance of having the disorder.

(Down, 2008)

Regardless of its form, individuals with Down syndrome manifest similar physical characteristics, making them easily recognizable among other individuals. The main physical characteristics follow:

Large than normal anterior fontanelle (soft spot)

Slanting eyes with folds of skin at the inner corner (epicanthic folds)

White spots on the iris of the eye (Brushfield spots or stars in the eyes)

Small, unusual-looking ears

Tongue protrusion

Flat bridge of the nose

Short neck

Transverse palmer crease

Gap between the first and second toes

Poor muscle tone (Hanson, 1987)

Moreover, individuals with Down syndrome suffer from various medical deficiencies, which vary from person to person. According to the National Down Syndrome Society (2011) various medical conditions, including but not limited to "attention deficit hyperactivity disorder, heart defects, Alzheimer's disease, neurological defects, blood defects, endocrine conditions, gastrointestinal tract conditions, vision impairments, autism, and atlantoaxial instability" (para. 1) may impact them.

Like their physical abilities, the learning styles of individuals with Down syndrome vary significantly from one person to the next. Learning styles are "aspects of personality that will influence [the] learners' achievement” (Borich, 2004). They are closely related to human intelligence and intellectual abilities. Studying 
the learning styles of individuals with Down syndrome necessities the examination of their intellectual abilities since the conditions has a drastic impact on human intellectual and physical abilities. All individuals with Down syndrome suffer from some type and extent of intellectual disability.

Almost all persons with DS exhibit some degree of intellectual impairment. There is, however, a great deal of variability in intellectual ability within this group, with the degree of mental retardation ranging from mild (IQs in the 55 to 70 range) to severe (IQs in the 25 to 40 range). In spite of this variation, DS persons exhibit a unique pattern of ability-disability. For example, when compared to other intellectually challenged persons, children with DS often have greater difficulty with cognitive activities involving speech and language, but display superior visual-motor skill. Thus, when one considers perceptual-motor and cognitive development in DS individuals, it is important to distinguish between performance and learning patterns that can be attributed to the general level of intellectual functioning, and the patterns associated with the syndrome (Down, 2005).

A research project to determine the extent to which intellectual abilities and IQs impacted the learning styles and reading process of individuals with Down syndrome would reveal that researchers did not take those factors into account. Rather, they tended to group all individuals with Down syndrome together regardless of their IQs and intellectual and physical abilities. Due to the lack of research concerning individual intellectual abilities and IQs, existing studies examine learning styles and approaches to the reading process at the general level.

\section{Learning Styles and Approach to Reading}

When studying learning styles and approaches to the reading process among individuals with Down syndrome, it is necessary to have two things in mind: the intellectual abilities of learners with Down syndrome and the quality of previous research on learning styles and the reading process. As we studying intellectual abilities and

Learning styles, which are highly connected to learners' intellectual abilities and IQs we must understand that Down syndrome, like other intellectual disabilities, does not impact all individuals equally. It may have a mild, medium, or severe impact on an individuals' intellectual and learning process. According to Bird, Cleave, and McConnell (2000), "children with DS [down syndrome] typically exhibit intellectual disabilities ${ }^{1}$ in the moderate to severe range. As well, they often experience language difficulties (especially expressive) greater than their nonverbal cognitive skills would predict" (p. 319).

In addition, the Cambridge Encyclopedia of Child Development indicates, "there is, however, a great deal of variability in intellectual ability within this group, with the degree of intellectual disability ranging from mild (IQs in the 55 to 70 range) to severe (IQs in the 25 to 40 range)" (Down, 2005). These individuals were practically left out learning opportunities simply because of the belief that they could not learn to read. According to Patricia Logan Oelwein, a leading researcher on the reading abilities of individuals with intellectual disabilities,

Before the late 1960 s, research on reading for students with moderate intellectual disability ${ }^{2} \quad$ was virtually nonexistent (Conners, 1992). The general belief was that

children with moderate retardation were only "trainable" and unable to learn

academics. They were, therefore, most often placed in classes labeled "trainable."

Children with Down syndrome were routinely given this label and placed in these

"trainable" classes (in places where these classes were available), based on the

diagnosis of Down syndrome, rather than on their abilities. Not only was research

on reading for these children virtually nonexistent, but opportunities for them to

learn to read were virtually nonexistent as well (Oelwein, 1995).

The fact is that learners with Down syndrome manifest a variety of intellectual abilities that shape their learning styles and their ability to learn to read differently. Previous research relating to this topic is very limited and general. Its limitation lies in the fact that the researchers behind it do not differentiate between the intellectual abilities of various Down syndrome learners though the condition's impact on individuals varies.

However, studies show that the learning styles and approaches to reading instructions of learners with Down syndrome are similar to those of regular learners in some ways regardless of their intellectual abilities. Studies shows that children (individuals) with Down syndrome pass through the same developmental stages as regular learners do. According to Nilholm (1999)

The development hypothesis implies that children with Down syndrome will pass through the same stages of development in a similar sequence as do children of average intelligence and that, give a certain mental age, Down syndrome children will display a "normal" structure of development. Thus, according to this position, a comparison of children with Down syndrome and intellectually average children, matched for the global measure of mental age, should reveal corresponding patterns of development in different sub-areas such as cognition and language. (p. 265)

\footnotetext{
${ }^{1}$ The term "mental retardation" is no longer used and is replaced with "intellectual disability." ${ }^{2}$ The term "mental retardation" is no longer used and is replaced with "intellectual disability."
} 
Furthermore, according to Nilholm (1999) "Children with Down syndrome appear to follow the same sequence of development as children of average intellectual ability, but certain areas of development fall below or above their mental age" (p. 265). Other scientists agree that children (individuals) with Down syndrome can learn to read. According to Bird et al. (2000), "many children with Down syndrome (DS) are capable of developing some reading and writing abilities" (p. 319). However, the extent to which they can learn to read is still unclear: "Little data exists, however, regarding how many of these children learn to read and to what extent reading is mastered" Bird et al. (2000).

Moreover, other researchers have found that children (individuals) with Down syndrome may learn to read and develop "non-traditional" modes of learning similarly to their peers with regular learning abilities. Studies show that, unlike regular readers, children (individuals) with Down syndrome may be capable of learning to read without phonological awareness, which is one of the leading factors in the achievement of the desired reading outcome.

Phonological awareness (PA) can be defined as the ability to focus consciously on the sound structure of language. It is typically assessed in tasks that involve the manipulation of phonological segments of language - for instance, breaking words down into their constituent syllables or phonemes (segmentation) or blending together sequences of individually uttered phonemes or syllables to form words (blending). PA has long been associated with the acquisition of alphabetic reading skills in children developing normally. (Cupples \& Iacono, 2000)

This puts to question the belief that phonological awareness is a prerequisite for learning to read.

In the first study of its kind, Cossu, Rossini, and Marshall (1993) tested 10 Italian children with

Down syndrome group-matched to typically developing controls on a word-level reading task (although the group with DS had lower mental ages). Real and nonsense words, both regularly and irregularly stressed, were included in the test of reading ability. Surprisingly, the children with DS read real and nonsense words equally well. Phonological awareness was measured using phoneme segmentation, deletion, synthesis, and oral spelling tasks. As a group, the children with DS performed more poorly than their reading-matched controls on all of these tasks. The authors interpreted their results to mean that "not all" children depend on phonological awareness in order to learn to read (Bird et al., 2000).

\section{Learning Styles and Educational Outcomes}

Understanding different learning styles is crucial when teaching learners with Down syndrome to read. Learners with Down syndrome are born with various deficiencies as well as intellectual disabilities that have different consequences. But the condition itself does not completely eliminate their intellectual and physical development.

The development hypothesis implies that children with Down syndrome will pass

through the same stages of development in a similar sequence as do children of

average intelligence and that, given a certain mental age, Down syndrome

children will display a "normal" structure of development (Nilholm, 1999).

Furthermore, their intellectual development goes through the same stages as that of children with average abilities: "Children with Down syndrome appear to follow the same sequence of development as children of average intellectual ability, but certain areas of development fall below or above their mental age" (Nilholm, 1999).

By exploring different learning styles, teachers could understand the learning process. This would enable them to teach their students to read because the learning process of learners with Down syndrome does not differ from that of regular students. Knowing different learning styles would also provide teachers with the opportunity to use different options when writing their lesson plans and would help them eliminate negative impacts on the learning process. All major learning styles can be incorporated into teaching strategies and would contribute to the learning process in their respective manners if properly applied. The major learning styles that we cover are associated with Hill's, Kolb’s, Dunn and Dunn, Grasha-Reichmann’s, and Gregorc.

\subsection{The Dunn and Dunn Learning Style}

The Dunn and Dunn learning style "takes into account multiple interacting elements, including environmental, sociological, emotional, and physical variables, each with its own sub-factors" (Jonassen \& Grabowski, 1993). It requires teachers to ensure that no negative variable from the environment disrupts students' learning process (which entitles learning to read in this case).

Environmental elements are primarily affiliated with the learning environment. Teachers have to ensure that objects that easily attract the attention of students with Down syndrome do not surround them and that the classroom has enough light, heat, and space to make the students feel comfortable and encourage them to focus on reading instructions. Sociological elements are affiliated with the people involved in the learning 
process. They include support from teachers, peers, and parents; teachers' knowledge and expertise regarding Down syndrome; and their ability to use proper teaching methods.

Emotional elements impact students personal feelings and may be beyond teachers' control. Learners have to be motivated to learn to read and lose their will to reading if they do not receive positive reinforcement. Understanding their feelings and their emotional intelligence is necessary for a successful learning process. And physical elements may be the most important part of the learning process for learners with Down syndrome. The learners need proper mobility, time to study, a specific time to take their lunch, and other accommodations that enable them to feel comfortable during the learning process. Physical accommodations may differ significantly depending on the severity of the learners' disability.

By carefully examining all the variables that Dunn and Dunn's learning style recognizes, teachers can ensure that all learners with Down syndrome are comfortable in their learning environment and that the learning process remains undisturbed.

\subsection{The Hill Learning Style}

Joseph Hill developed the Hill learning style, which "refers to the way students receive and process information to derive meaning from their environment and personal experience" (Jonassen \& Grabowski, 1993). According to him, "Educational cognitive style is the Cartesian product of four sets of variables: symbols and their meanings, cultural determinants, modalities of inference and educational memory" (Jonassen \& Grabowski, 1993).

Teachers who use the Hill learning style when giving reading instructions should mostly be concerned with two variables: symbols and their meaning and educational memory. Reading is the process of learning different symbols (letters of the alphabet in this case) and proper memorization. The first step in the reading process for learners with Down syndrome, as well as regular students, is learning to recognize letters of the alphabet, which are later connected into words and sentences.

Learning different symbols requires memorization, and this involves educational memory. Knowing how to read is an ability that one cannot forget easily. The objective is to help students to improve their reading abilities and to prevent them from forgetting newly learned material. Regarding educational memory, teachers have to ensure that students store (remember) all learned information in their long-term memory when they are learning to read. They can achieve this through constant experimentation and practice, which Kolb's learning style explains and defines to a greater extent Understanding learners' educational memory helps teachers properly allocate teaching time since some learners may need extra time to remember certain learning material.

\subsection{The Kolb Learning Style}

Understanding the Kolb learning style most likely helps teachers properly implement learning activities and teaching methods. The most helpful features of the Kolb learning style are the four learning styles: "concrete experience (CE), reflective observation (RO), abstract conceptualization (AC), and active experimentation (AE)” (Jonassen \& Grabowski, 1993).

When teaching learners with Down syndrome to read, teachers should design teaching instructions on the basis of the learners' prior knowledge (concrete experience), their ability to follow instructions without disturbance (reflective observation), their ability to learn and comprehend the learning material (abstract conceptualization), and their ability to maintain newly learned knowledge through constant practice (active experimentation). Understanding the learning modes involved in the Kolb learning style can help the teachers comprehend the learning process of their learners and construct lesson plans.

\subsection{The Grasha-Reichmann Learning Style}

Though this learning style originally developed from the examination of college students, one can very easily apply the theory to any classroom. The Grasha-Reichmann learning style "can be classified as a social interaction scale because it deals with patterns of preferred styles for interacting with teachers and fellow students in a learning environment rather than how information is perceived or organized" (Jonassen \& Grabowski, 1993).

When interacting with their students, teachers engage in non-directive teaching and serve more as advisors than teachers. If they experience good interaction with their teachers and peers, learners with Down syndrome are more comfortable learning since a friendly, caring environment is necessary for their growth and development. According to the Encyclopedia of Health, "people with Down syndrome are usually exceptionally happy, gentle, and loving. As children, they need loving care and extra attention to make sure their minds are stimulated. They need special teaching to make sure that they develop as much as possible" (Hildyard, 2003).

Creating a friendly environment through interaction between teachers and learners has a positive impact on the teaching process. How well teachers and learners communicate with each other has an enormous impact on their learning and teaching processes. Teachers have to ensure that learners with Down syndrome 
are grouped with learners with whom they feel comfortable learning and who will inspire them to learn to read.

\subsection{The Gregorc Learning Style}

In the Gregorc learning style, teachers who teach learners with Down syndrome to read have to recognize abstract sequential learners, concrete sequential learners, and ordering preference.

An abstract sequential learner "is characterized by strengths in the area of decoding written, verbal, and image symbols" (Jonassen \& Grabowski, 1993). Becoming an abstract sequential learner is a significant step in learning to recognize written symbols (letters of the alphabet) that leads to reading progress. In additions, learners with Down syndrome, as well as those with any intellectual disabilities, have to experiment with learning material and newly learned information so that they can store them properly in long-term memory. As for concrete sequential learners they are "characterized by the

preference for extracting information through hands-on experience" (Jonassen \& Grabowski, 1993). Teaching objectives are best achieved when these learners are involved in constant practice, that is, reading practice. Through their practice to recognize letters of the alphabet (symbols) and active reading practice, learners are able to store reading skills in their long-term memory.

One important feature of the Gregorc learning style, which teachers have to observe closely while teaching learners to read is the ordering preference. It "refers to the way one arranges, prioritizes, and uses information in either a sequential or random order, or in some combination” (Jonassen \& Grabowski, 1993). That means that learners have to learn to organize letters, words, and sentences to produce meaning.

\section{Teaching Strategies for the Reading Process of Students with Down Syndrome 5.1. Letter/Number Recognition}

This teaching strategy is primarily used to teach learners with Down syndrome to recognize letters of the alphabet and numbers. The purpose of the reading process is to teach them to "read" letters as well as numbers. That means that learners should be able to recognize the letters and the numbers at the first stage of learning. Then they can move to the next stage, at which they will be able to read words and sentences. This teaching strategy focuses on reflective observation and active experimentation, which are two learning modes that the Kolb learning style recognizes.

The first step involves providing learners with cards (of any size). On each card, there should be a capital letter, the corresponding lower-case letter, and a picture of an object whose name begins with that particular letter. If numbers are the topic the teachers provide the learners with cards, each of which features a numbers and an illustration that represents that number. An example follows: When teaching learners to recognize the letter "A," the card that the teachers use shows a capital "A," a lower-case "a" and the picture of an automobile. The teachers then repeat the sound of the letter until the learners can pronounce it on their own.

Once it is evident that the learners can pronounce a letter (or number) on their own, the teacher ask them to pronounce it five times by giving them a verbal affirmation every time they do that. It is possible to repeat this process as many times as is necessary until the learners learn to recognize and pronounce the letter or number in question. The process may take the following form:

Teacher: What is this letter?

Students: A.

Teacher: Good! What it this letter again?

Student: A.

Teacher: Excellent! What is this letter one more time?

Student: A.

Teacher: Wonderful! What is this letter again?

Student: A.

Teacher: Amazing! And what is this letter one more time?

Student: A.

Teacher: Very good! You did an excellent job.

The teachers may design the sample letter/number cards or they use the ones in learning software programs if the learners prefer to use the computer while learning. These are some samples of letter/number cards that may be used for this teaching method. 

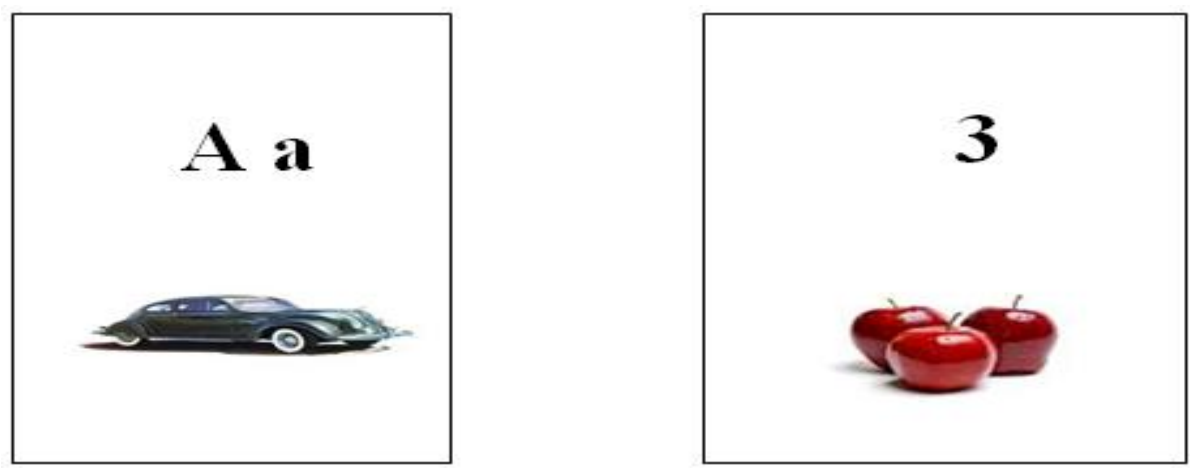

Figure-1. Letters of the alphabet and numbers.

\subsection{Letter/Number Discrimination}

The second teaching strategy, letter/number discrimination, is used to teach learners to discriminate between different letters and numbers. Once the learners have learned to pronounce certain letters and numbers, the teachers have to teach them to discriminate between them and others. For example, the teachers may present students with a group of letters and numbers and ask the learners to single out certain letters or numbers from it. The objective of this teaching method is to teach learners to recognize symbols (letters and numbers) and to discriminate between them and others. This teaching strategy helps learners become abstract sequential learners. In the Gregorc learning style, the abstract sequential learner "is characterized by strengths in the area of decoding written, verbal, and image symbols" (Jonassen \& Grabowski, 1993). Learners may not be abstract sequential learners by nature but they must be able to adapt to this learning style because discrimination between different symbols and concepts is an essential part of a successful learning process. The learning styles used in this teaching method include the Hill learning style (symbols and their meaning), the Kolb learning style (abstract conceptualization and active experimentation), and the Gregorc learning style (abstract perception). This teaching strategy can involve one presenting learners with written material or an electronic copy of the same (computer software). The simple task involving his teaching strategy is presented on the following page.

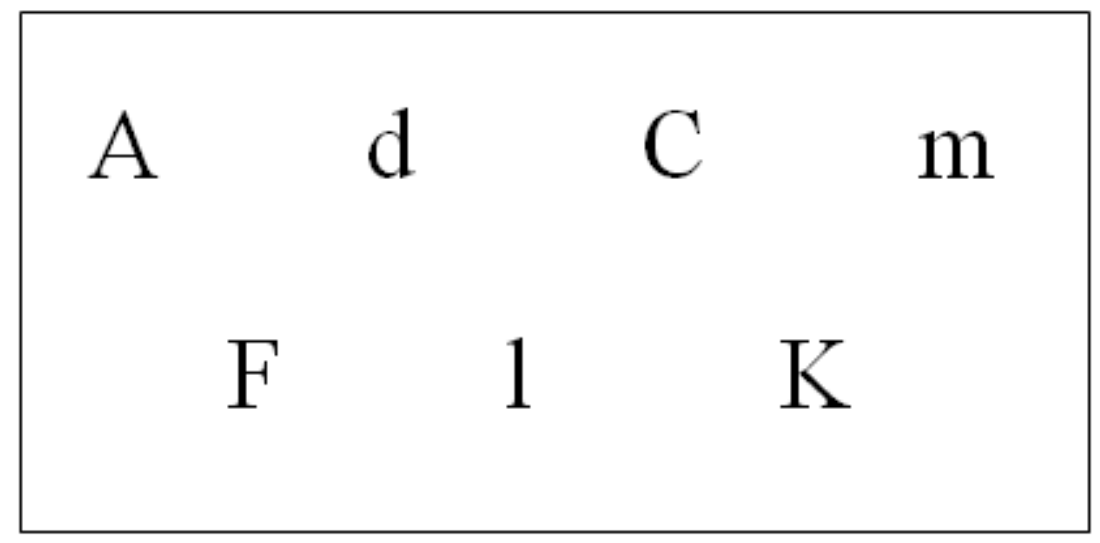

Figure-2. Circle letters "M" and "f."

\subsection{Letter/Number Meaning}

Knowing the meaning of letters and numbers brings learners one step toward reading comprehension. The objective of this teaching strategy is to teach them phonological awareness and to help them to recognize letters when they are incorporated into a word or a sentence. Once teachers teach learners how each letter contributes to the formation of a sentence, they can proceed to the next step; word recognition. This teaching strategy matches all learning styles but learners may not be able to assimilate it within short period of time. It can turn into a long learning process that helps learners become acquainted with phonemic segmentation. Phonemic segmentation is "the ability to isolate and identify sounds in words" (Jonassen \& Grabowski, 1993).

In this teaching strategy, the focus is on the Kolb learning style and the active experimentation mode. Teachers present learners with one letter and a few pictures of different objects. They then ask the learners to single out objects whose names begin or end with that letter. The teachers may show them several different objects and ask them to identify them all together. Like the previous teaching strategies, this one can involve written material or an electronic copy of the material (through computer software) depending on teachers' or learners' learning preferences.

Teacher may even try to teach learners with good reading abilities to group together objects that rhyme with a certain word. For example, the assignment may involve the word "mug" and the pictures of different 
objects, including a "rug." Learners would have to match the word "mug" with the word "rug" due to the rhyme. However, the rhyming strategy would only apply to learners with advanced reading skills. The following sample illustrates this teaching strategy.
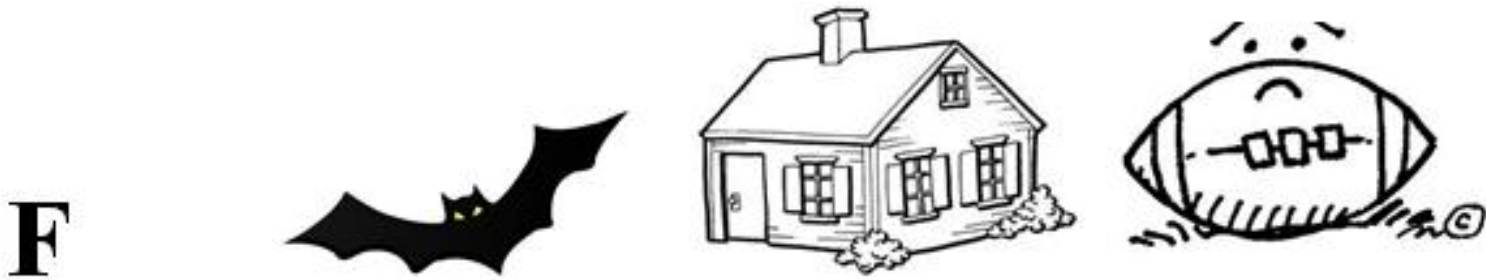

Figure-3. Circle the object whose name begins with letter "F".

\subsection{Word Recognition}

Word recognition is the fourth teaching strategy. It is similar to letter/mumber recognition but involves words rather than letters or numbers. This teaching strategy enjoys the influence of all five learning styles (the Hill, Kolb, Dunn and Dunn, Grasha-Reichman, and Gregorc learning styles). It involves showing cards that include a word and the picture that the word represents. As in the letter/number-recognition teaching strategy, the teacher shows a picture of a certain word and has the learners pronounce this word five times. The learners can learn up to five words in one week or just one word, depending on the impact of Down syndrome on the learning process. Once the learners become familiar with the teaching strategy, the teacher may remove the pictures from the word cards and present only the words. To facilitate this teaching/learning method, the teacher may ask the learners to write the newly learned word several times so that they can practice reading and writing at the same time and memorize the newly learned words.

The incorporation of writing is of significance because, this time, the learners must learn a word, which is a group of different letters, not just one letter or a number. This may present some difficulties for some learners, but incorporating the writing strategy along with the reading strategy may facilitate the achievement of the desired learning outcome. Teachers should begin this teaching strategy with simple words (such as: "mom," "dad," "sister," "brother,"), or words that are used in the school setting on a regular basis (for instance, "pencil," "paper," "classroom," "bathroom," "lunch," "school,"). During this teaching strategy, the teachers have to ensure that the learners understand the meanings of the words that look similar (those that rhyme). The sample teaching material for this teaching strategy appears on the following page.
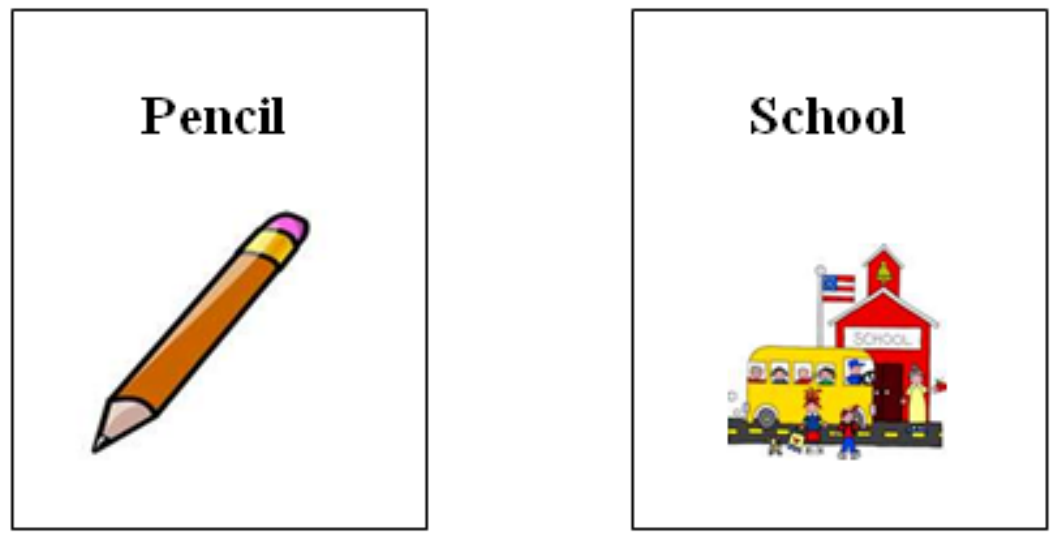

Figure-4. Pronounce each word that you see on the card.

\subsection{Word Discrimination}

The word-discrimination teaching strategy teaches learners to recognize certain words when they appear among other words. This prevents them from becoming confused when they see a sentence with many different words. Knowing how to recognize a certain word among other words indicates that the learners know the meaning and pronunciation of that word.

This teaching strategy is ideal for learners who have computer software that will allow them to see a group of words or a sentence and tell them which word to select by clicking on it using computer mouse. Alternatively, teachers may use word cards if computers are not available or if the learners prefer that.

This teaching strategy has three steps. The first one entails presenting a word surrounded by different symbols and asking learners to single it out. That word has to be spoken out loud so that learners hear it sound before making a selection. The second step involves presenting a group of different words and having learners single out one or more after the teacher verbally pronounces them. And the third step entails 
presenting a group of words that rhyme and asking the learners to single out one word. The teacher should only used this when the learners have become familiar with letters and are fluent in word recognition.

This teaching method may not be successful with learners with Down syndrome who experience severe intellectual disabilities. Such learners may need long-term practice and, unfortunately, may not achieve satisfactory learning outcomes. The sample material for this teaching strategy appears on the following page.
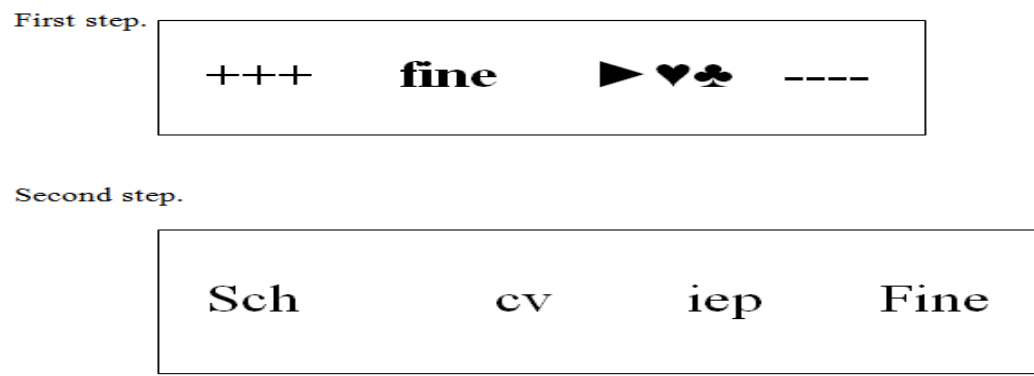

Third step.

\section{Mine pine Fine Line}

Figure-5. Circle word "Fine" on the following cards.

\subsection{Word Meaning}

Understanding the meaning of a single word brings learners one step closer to achieving reading comprehension. That means that they have to understand what a single word represents. Word meaning can involve a teacher presenting different words to learners and having the learners connect them with the pictures that they present. The teacher may read the word so that the learners hear the sound or may provide them with a list of different words and have them select the picture that represents the meaning of that particular word. Like previous teaching strategies, this one can take the form of a classroom activity or a computer and electronic software.

Furthermore, when working with learners with Down syndrome in advanced classes, teachers may pronounce a word and ask them to verbally explain what the word means or provide an example sentence that includes it. This teaching strategy can also accompany a writing exercise. Learners with Down syndrome who have advanced learning skills can do a writing exercise. Teachers may ask them to write an explanation of one word or to write sentences that include the words.

In my teaching practice, this "word meaning" teaching strategy involves written material: Learners see a specific word that they have to identify on one side and the different illustrations that the word represents. The first step involves one word and only two illustrations, then more words and illustrations follow as the learning process progresses. Once it is apparent that the learners can read the word and explain its meaning, it is possible to move to the next step of the reading process and to start working with whole sentences. The sample teaching material for this teaching strategy appears below.

\section{House}
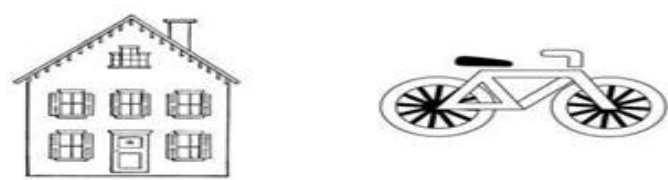

\section{Owl}
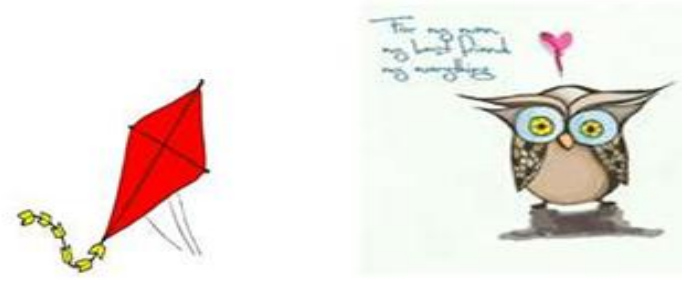

Figure-6. Read the word on the left side and circle the picture that represents that word on the right side. 


\subsection{Sentence Recognition}

Learning sentence recognition and moving beyond learning letters, numbers, and words, may not be appropriate for all learners with Down syndrome. Those who have certain intellectual disabilities may not be able to reach this level that presents them with the opportunity to read and understand whole sentences. Those who master the reading and comprehension of single words receive instructions on reading simple sentences first then slowly progressing to more complex sentences, paragraphs, and perhaps, short stories. This teaching strategy begins with the presentation of short, simple sentences on the blackboard, on paper, or on a computer. Learners read them until they become fluent in reading. Numerous software products can help learners to learn to read too.

In this teaching strategy, teachers should ensure that learners pronounce each word correctly, keep a medium reading tempo, and adapt their voice to periods, exclamation points, question marks, and commas. Improving reading fluency should be the main objective at this point. Teachers should focus on fluency because some learners with Down syndrome may not be able to comprehend words when they are grouped together. Once learners become fluent in reading sentences or achieve partial fluency at least, they can move to the next step, which teaches word discrimination and meaning. At this point, learners do not have to focus on comprehension but only on the fluency of reading.

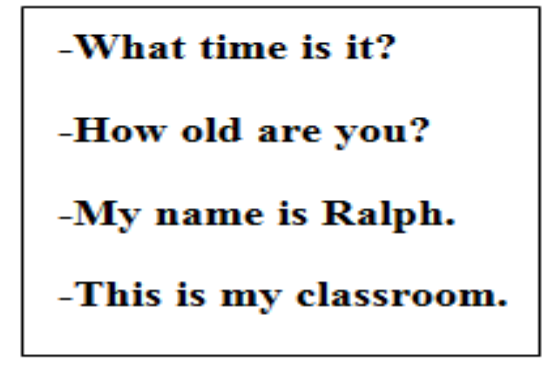

Figure-7. Read the following sentences.

\subsection{Sentence Discrimination}

Once learners are able to read a whole sentence or a group of sentences, they can move slowly towards reading comprehension. Learners who engage in this reading strategy should understand the meaning of the sentence. Understanding the meanings of symbols is the key component of this teaching strategy, which the Hill and Gregorc learning styles recognize.

Learners with Down syndrome, as well as any other learners, who are trying to learn to read may become fluent in reading. But their fluency is not an indicator of their reading comprehension. In this teaching strategy, teachers have to use teaching material with at least three different sentences and one illustration that represents the meaning of one sentence. The learners have to read each sentence aloud and select the one that represents the illustration. When designing this teaching strategy, teachers have to be careful not to select sentences that are confusing or similar to each other. Moreover, they should ensure that only one sentence can be directly connected to the illustration. During this teaching strategy, the teachers do not provide reading assistance to the learners; they only help them to stay on task. At this point, the learners should be fluent in reading or should, at least, able to read without making major mistakes. Comprehension is the main objective that learners must achieve with this teaching method before they move to a more complex learning level. The teacher may design the teaching material for this teaching strategy or obtain it using electronic software.

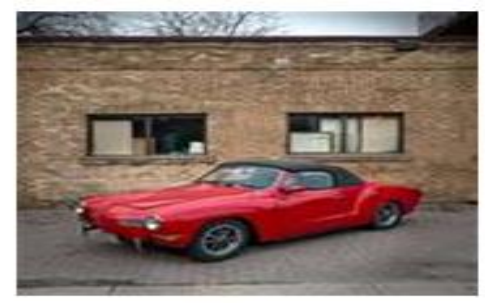

\footnotetext{
-A little yellow fish in the aquarium.

-Little red car on the street.

-Two funny animals jumping.
}

Figure-8. Circle the sentence that describes the picture your see. 


\subsection{Sentence Meaning}

Teaching the meaning of a sole sentence is the main objective of teaching learners with Down syndrome to read. Unlike the previous teaching strategy of sentence discrimination, the sentence-meaning strategy does not provide learners with clues, such as illustrations, and it only includes one sentence.

Teachers should write one sentence on the board or provide cards with different sentences that give learners certain tasks to perform. After reading a sentence by themselves, learners should be able to perform the task that, it assigns to them. The teachers should not help the learners to read. They are only facilitators or observers, and their job is to observe the actions of the learners after they read the sentence. The teachers should only intervene when the learners fail to read the sentence properly or to comprehend it. That is an indication that the learners need additional reading practice to improve their reading comprehension.

The learners get the reading material alone. They do not get illustrations that would give them some clue as to the meaning of the sentence. This teaching strategy is only appropriate when learners have become fluent in reading and comprehension and it may not be suitable for students with Down syndrome who have severe intellectual disabilities. Once it is apparent that students are comfortable with this learning strategy, they can progress to the more complex reading strategies that grant them the opportunity to read short stories.

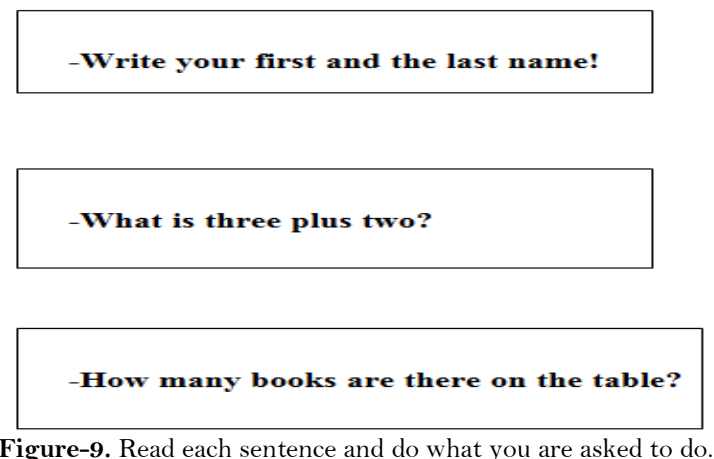

\subsection{Reading and Writing for Meaning}

Reading and Writing for Meaning is the last teaching method that teachers use to teach learners with Down syndrome to read. It is appropriate for teaching learners with advanced reading skills to read.

Teachers who use reading and writing for meaning primarily focus on advanced reading material such as booklets, novels, short stories, magazines, and any other reading material they find appropriate for their learners. The main objective of the teaching style is to teach learners to read certain reading material and to have them provide a written summary of what they have read. It teaches the learners all aspects of the reading process that the previous teaching styles involve. The learners are able to make use of their knowledge of word and sentence recognition, reading fluency, an comprehension and even their writing skills.

In this teaching strategy, teachers assign a reading assignment and read it along with their learners. They have to provide scaffolding at first then to slowly allow the learners to read on their own. During the reading, the teachers have to make sure that the learners understand (comprehend) the reading material. Once the learners complete the reading, they have to engage in a short writing assignment to explain what they learned from it. If reading material consists of several chapters, the learners may get a writing assignment after each chapter.

This teaching method also teaches the learners to become independent readers who can read and comprehend reading material on their own. The teachers only use it on the learners with advanced reading skills who have minor intellectual disabilities.

\section{References}

Bird, E. K., Cleave, P. L., \& McConnell, L. (2000). Reading and phonological awareness in children with down syndrome: A longitudinal study. American Journal of Speech-Language Pathology, 9(4), 319-330.

Borich, G. D. (2004). Effective teaching methods (5th ed.). Upper Saddle River, NJ: Pearson Education, Inc.

Conners, F. A. (1992). Reading instruction for students with moderate mental retardation : Review and analysis of research. American Journal of Mental Deficiency, 96(6), 577-597.

Cossu, G., Rossini, F., \& Marshall, J. C. (1993). When reading is acquired but phonemic awareness is not: A study of literacy in Down syndrome. Cognition, 46(2), 129-138.

Cupples, L., \& Iacono, T. (2000). Phonological awareness and oral reading skill in children with down syndrome. Journal of Speech, Language, and Hearing Research, 43(3), 595-608.

$\begin{array}{lllllll}\text { Down, } & \begin{array}{l}\text { S. (2005). In Cambridge encyclopedia of child development. } \\ \text { http://www.xreferplus.com.proxyl.ncu.edu/entry/cupchilddev/down_s_syndrome. }\end{array} & \text { Retrieved } & \text { from: } \\ \text { Down, } & \text { S. (2008). } & \text { In the Columbia } & \text { encyclopedia. } & \text { Retrieved } & \text { from }\end{array}$ http://www.xreferplus.com.proxy 1.ncu.edu/topic/down_syndrome. 
Down, S. (2009). In Mosby's dictionary of medicine, nursing, \& health professions. Retrieved from http://www.xreferplus.com.proxy 1.ncu.edu/entry/ehsmosbymed/down_syndrome.

Hanson, M. J. (1987). Teaching the infant with down syndrome (2nd ed.). Austin: TX: PRO-ED, Inc.

Hildyard, A. (2003). Down syndrome. In encyclopedia of health. Tarrytown, NY: Marshall Cavendish Corporation, 5, $244-245$.

Jonassen, D. H., \& Grabowski, B. L. (1993). Handbook of individual differences, learning \& instruction. Hillsdale, NJ: Lawrence Erlbaum Associates, Inc.

http://ndss.org/index.php?option=com_content\&view=article\&id=54\&Itemid=74. [Accessed April 12, 2001$].$

Nilholm, C. (1999). The zone of proximal development: A comparison of children with down syndrome and typical children. Journal of Intellectual ङ Developmental Disability, 24(3), 265-279.

Oelwein, P. L. (1995). Topics in Down syndrome: Teaching reading to children with down syndrome, a guide for parents and teachers. Bethesda, MD: Woodbine. 